\title{
Late stage diagnosis of mucinous adenocarcinoma of the appendix: a case report of an unusual tumor with a rare presentation
}

\author{
Katerina Roma ${ }^{1 *}$ (D), Mark Baldwin ${ }^{1}$, Daniel Sedmak ${ }^{5}$, Matthew Silva ${ }^{4}$, William Stellar ${ }^{2}$ and Gina Many ${ }^{3}$
}

\begin{abstract}
Background: The incidence of mucinous appendiceal adenocarcinomas (MAA) has increased over the past three decades. Advanced stage tumor diagnosis is likely attributable to non-specific findings. Here we describe advanced stage appendiceal MAA presenting as inguinal ulcers, scrotal abscesses, and other nonspecific symptoms. To our knowledge, this is the first report of MAA presenting as inguinal pain with inflamed phlegmonous tissue and scrotal abscess.

Case presentation: A 67-year-old male presented to a rural facility complaining of weight-loss, fatigue, hematuria, dysuria, painful right inguinal ulceration, and right scrotal abscess drainage. Computed tomography of the abdomen and pelvis revealed a distended appendix $(>1.3 \mathrm{~cm})$ and a fistula between the appendix, urinary bladder, right scrotum, and right groin. Laparoscopic appendectomy was performed and diagnosed as MAA. After a right hemicolectomy, the MAA was staged as pT3b pNO MO G2.

Conclusion: This case highlights a unique presentation of late stage appendiceal MAA. Due to the increased incidence of appendiceal MAAs, reports of unique clinical features are needed to facilitate early diagnosis and intervention, especially in rural settings with limited access to specialists.
\end{abstract}

Keywords: Case report, Appendiceal cancer, Inguinal pain, Inguinal ulcer, Scrotal abscess, Hematuria, Bladder mass

\section{Background}

Appendiceal neoplasms are rare, accounting for less than $1 \%$ of intestinal neoplasms [1]. There are three different types of appendiceal neoplasms, which are defined by the World Health Organization as mucinous adenoma, low-grade appendiceal mucinous neoplasm (LAMN), and mucinous appendiceal adenocarcinoma (MAA) [2]. Among primary malignant neoplasms of the appendix, MAA presents most frequently (37\% of all appendiceal neoplasms) and its incidence in the United States is

\footnotetext{
* Correspondence: kroma@pnwu.edu

'Pacific Northwest University of Health Sciences, Yakima, WA 98901, USA Full list of author information is available at the end of the article
}

rising $[3,4]$. Mucinous adenomas are characterized as benign masses confined to the mucosa with intact muscularis. LAMN and mucinous adenocarcinoma have the potential to cause pseudomyxoma peritonei (PMP) due to excessive mucin production. PMP is a spread of gelatinous material (mucin) from the lumen of the appendix into the abdominal cavity, morphologically referred to as mucoceles [5]. The median time to PMP development after MAA onset is $\sim 2$ years [6]. With peritoneal metastasis, the five-year survival rate for mucinous adenocarcinoma is reported as low as $25 \%$ [6]. In addition, mucinous adenocarcinomas have a relatively higher risk for hematogenous and nodal metastasis [6]. Therefore,

C C The Author(s). 2020 Open Access This article is licensed under a Creative Commons Attribution 4.0 International License, which permits use, sharing, adaptation, distribution and reproduction in any medium or format, as long as you give appropriate credit to the original author(s) and the source, provide a link to the Creative Commons licence, and indicate if changes were made. The images or other third party material in this article are included in the article's Creative Commons licence, unless indicated otherwise in a credit line to the material. If material is not included in the article's Creative Commons licence and your intended use is not permitted by statutory regulation or exceeds the permitted use, you will need to obtain permission directly from the copyright holder. To view a copy of this licence, visit http://creativecommons.org/licenses/by/4.0/ The Creative Commons Public Domain Dedication waiver (http://creativecommons.org/publicdomain/zero/1.0/) applies to the data made available in this article, unless otherwise stated in a credit line to the data. 
the early detection of a mucinous appendiceal neoplasm is imperative.

Despite their clinical severity, the prospective clinical diagnosis of mucinous neoplasms may be difficult, as the symptoms are typically minimal or nonspecific. If symptoms do occur, mucinous neoplasms often present as abdominal pain, weight loss, nausea, vomiting, a palpable mass, and acute appendicitis. Additionally, the prevalence and clinical presentations may differ between sexes [5, 6]. Appendiceal mucoceles are more common in women (4:1) and therefore may be misdiagnosed as gynecological pathologies such as a cystic right adnexal mass of the ovary or fallopian tube [5, 6]. MAA may also be mistaken for a urinary tract infection or bladder cancer as it can present with hematuria in both men and women [7-16]. In rare cases, MAAs present as scrotal pain due to metastasis and may even been found within de Garengeot hernias [17, 18], which are femoral hernias containing the appendix.

Half of all mucinous neoplasms are diagnosed through incidental appendectomies or imaging studies [19]. By the time they are diagnosed, the neoplasms are often at an advanced stage [3]. Here, we report a rare patient presentation with late-stage MAA and review the common and unique clinical presentations with imaging findings to aid in future early diagnosis of MAA in undifferentiated patients.

\section{Case presentation}

A 67-year-old male presented complaining of a right linear inguinal crease pustule that had persisted for 2 weeks. The pertinent vital signs were a temperature of $36.4{ }^{\circ} \mathrm{C}$, and a weight of $91.6 \mathrm{~kg}$. The patient was a current smoker with a $1 / 2$ pack per day habit for the past 55 years. Past medical history was unremarkable with a history of right inguinal hernia repair and vasectomy. The patient was not taking any medications or over the counter supplements. His family history was unremarkable. The abdominal exam was remarkable for a small inguinal hernia and a 1-cm healed ulcer in the right inguinal area.

Four months later, the patient returned complaining of increased urinary frequency, hematuria, and scrotal pain lasting several days. There was no history of chills, nausea, vomiting, costovertebral angle (CVA) tenderness, or abdominal pain. His temperature was $38.0^{\circ} \mathrm{C}$. Urinalysis revealed +1 blood, +1 leukocyte, $\mathrm{WBC}>182$ $\mathrm{HPF}, \mathrm{RBC}>61 \mathrm{HPF}$, and positive for bacteria. Urine culture was positive for Escherichia coli and ciprofloxacin was subsequently prescribed. An ultrasound of the scrotum was not performed. The patient's symptoms had resolved three weeks later at follow-up; however, the patient's weight had decreased by $5.4 \mathrm{~kg}$. A urinalysis again demonstrated $22 \mathrm{WBC} / \mathrm{HPF}$ and RBCs, and the follow-up culture was negative. Other labs were obtained, including CBC, CMP, and PSA, which were unremarkable.

Two months later, the patient returned complaining of posterior scrotum abscess drainage. He was afebrile with no palpable testicular mass or tenderness. However, there was thickening and serosanguinous drainage over the right testicle. The patient was treated with trimethoprim/sulfamethoxazole and cephalexin and was referred to urology for his scrotal abscess. Later, computed tomography (CT) of the abdomen and pelvis with contrast revealed a distended appendix $(>1.3 \mathrm{~cm})$ and a fistula located between the appendix, urinary bladder, right scrotum, and right groin (Fig. 1a and b). The patient was referred for colorectal surgery.
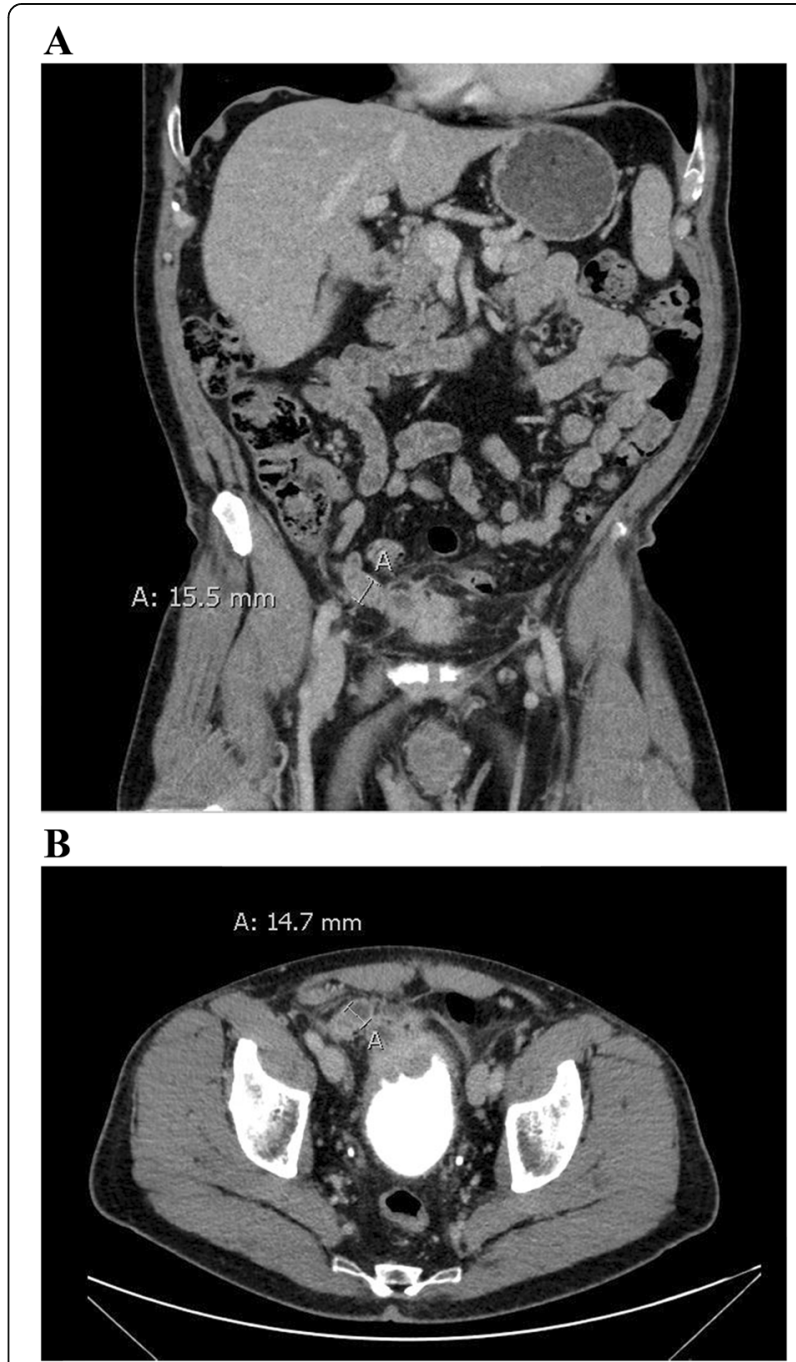

Fig. $1 \subset T$ with contrast of abdomen and pelvis. a. $C T$ with contrast of abdomen and pelvis (coronal plane). An estimated appendiceal luminal dilation of $15.5 \mathrm{~mm}$ (left) with fistula to the bladder is displayed. b. CT with contrast of abdomen and pelvis (axial plane). An estimated appendiceal luminal dilation of $14.7 \mathrm{~mm}$ (left), with fistula formation to the bladder is displayed 


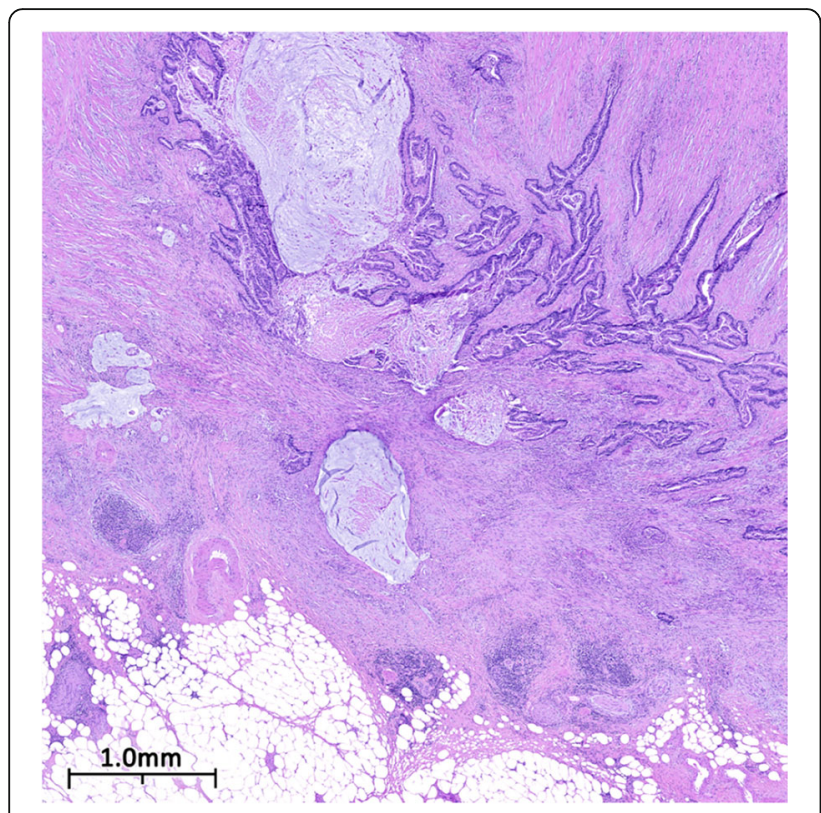

Fig. 2 Low power photomicrograph of dissected appendiceal tissue. Figure 2. Low power photomicrograph of H\&E stain showing moderately differentiated branching neoplastic glands focally distended by mucinous material and invading the muscularis. Mucinous pools partially lined with neoplastic epithelium are also present

Subsequently, a shave biopsy of a scrotal abscess lesion revealed granulated tissue. Cystoscopy showed a large mass in the anterior right bladder wall. Transurethral resection of the bladder tumor (TURBT) revealed the presence of urothelial mucosa consistent with chronic inflammation. A bone scan did not reveal evidence of metastatic disease.

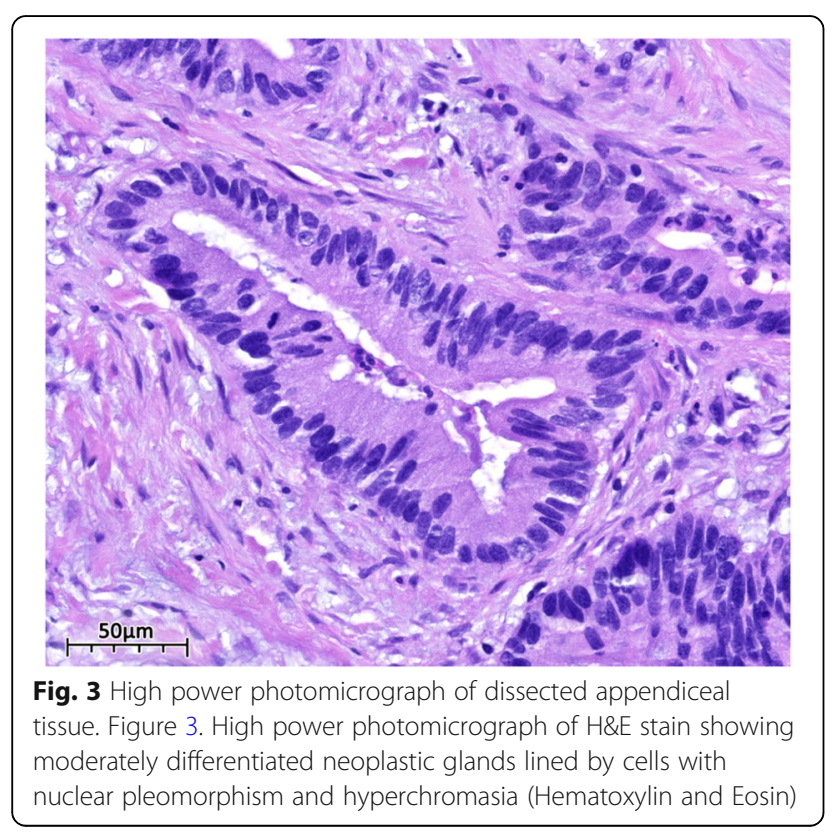

The patient then underwent a laparoscopic appendectomy, where an abundance of mucin was observed. This was followed by a right hemicolectomy, partial omentectomy, and lymph node dissection. Microscopic examination of the appendix revealed a mucinous adenocarcinoma that had invaded through the muscularis propria into the subserosa without lymphovascular invasion. The tumor was staged as pT3b pN0 M0 G2 (Figs. 2 and 3). After discharge, the patient was referred to oncology and FOLFOX regimen (levoleucovorin, fluorouracil, and oxaliplatin) was recommended.

\section{Discussion and conclusion Unique patient presentations}

We describe a unique presentation of appendiceal MAA. To our knowledge, this is the first case study describing the diagnosis of late-stage appendiceal MAA presenting with scrotal pain, abscess, and inguinal drainage. CT imaging revealed appendix distension with $>1.3 \mathrm{~cm}$ luminal dilation (Figs. 1 and 2), which raises the strong suspicion for MAA [20]. Several case studies have reported right inguinal and right scrotal pain as presenting symptoms in a patient with acute appendicitis or a perforation of an appendiceal abscess [21-24].

\section{Image findings}

Appendiceal mucoceles are frequently found using CT. Mucoceles can become inflamed and have a similar appearance on $\mathrm{CT}$ to acute appendicitis without mucocele. A CT cannot distinguish between benign (mucosal hyperplasia, retention cyst, mucinous adenoma) and malignant (LAMN, mucinous carcinoma) causes of appendiceal mucoceles [6]. However, few findings are specific for appendiceal neoplasms. The presence of appendiceal mural calcifications on CT is reported as $99.3 \%$ specific for appendiceal epithelial neoplasms [25]. Cystic dilation of the appendix, mural calcification, or maximum luminal dilation $>1.3 \mathrm{~cm}$ with $\mathrm{CT}$ have a $71 \%$ sensitivity, $94 \%$ specificity, and overall diagnostic accuracy of $88 \%$ for coexisting mucoceles with acute appendicitis [20].

Due to the increased incidence and frequent advanced stage diagnosis of mucinous appendiceal adenocarcinomas (MAA), the need of case reports highlighting unique features of this tumor type is imperative. This case highlights a late stage diagnosis and unique clinical features of MAA.

\footnotetext{
Abbreviations

MAA: Mucinous appendiceal adenocarcinoma; PMP: Pseudomyxoma peritonei; TURBT: Transurethral resection of bladder tumor; CT: Computed tomography; LAMN: Low-grade appendiceal mucinous neoplasm; HIPE C: Heated intraperitoneal chemotherapy; H\&E: Hematoxylin and Eosin
}

\section{Acknowledgments}

The authors thank Dr. Jim Rhodes Ph.D. and Dr. Douglas Shearer M.D. Ph.D. for taking images from previously obtained pathology slides. We also thank Dr. Juergen Mueller M.D. and Dr. Albert Brady M.D. for providing their expertise and adding helpful information to this paper. 


\section{Authors' contributions}

K.R. and W.S. conceived of the presented idea. K.R. wrote and drafted the manuscript. G.M. and M.B. supervised the project. D.S. and M.S. interpreted the images and provided their expert analysis to the paper. All authors aided in the project design, critical evaluation, and editing of the manuscript. All authors have read and approved the manuscript.

\section{Funding}

Not funded.

\section{Availability of data and materials \\ Not applicable.}

\section{Ethics approval and consent to participate}

Not Applicable.

\section{Consent for publication}

Written consent was obtained from the patient for the publication of his data.

\section{Competing interests}

None declared.

\section{Author details}

'Pacific Northwest University of Health Sciences, Yakima, WA 98901, USA. 2Veteran's Hospital, Roseburg, OR 97471, USA. ${ }^{3}$ Community Health of Central Washington, Yakima, WA 98901, USA. ${ }^{4}$ Cascade Surgical Partners, Yakima, WA 98901, USA. ${ }^{5}$ The Ohio State University, Columbus, OH 43210, USA.

Received: 27 June 2019 Accepted: 9 July 2020

Published online: 21 August 2020

\section{References}

1. Connor, S. J., Hanna, G. B., \& Frizelle, F. A. (1998). Appendiceal tumors. Dis Colon rectum, 41(1), 75-80.

2. Bosman, F. T., Carneiro, F., Hruban, R. H., \& Theise, N. D. (2010). WHO classification of tumours of the digestive system (no. Ed. 4). World Health Organization.

3. Overman MJ, Fournier K, Hu CY, et al. Improving the AJCC/TNM staging for adenocarcinomas of the appendix: the prognostic impact of histological grade. Ann Surg. 2013;257(6):1072-8. McCusker ME, Cote TR, Clegg LX et al. Primary malignant neoplasms of the appendix: A population-based study from the surveillance, epidemiology and end-results program, 1973-1998. Cancer 2002; 94:3307-3312.

4. Xie, G., Liu, Y., Jiang, Y. et al. Epidemiology and survival outcomes of mucinous adenocarcinomas: a SEER population-based study. Sci Rep 8, 6117 (2018). https://doi.org/10.1038/s41598-018-24540-7.

5. Tirumani SH, Fraser-Hill M, Auer R, Shabana W, Walsh C, Lee F, Ryan JG. Mucinous neoplasms of the appendix: a current comprehensive clinicopathologic and imaging review. Cancer Imaging. 2013;13(1):14.

6. Van Hooser A, Williams TR, Myers DT. Mucinous appendiceal neoplasms: pathologic classification, clinical implications, imaging spectrum and mimics. Abdominal Radiology. 2018:1-10.

7. Tripodi J, Perlmutter S, Rudansky S, Kim DK, Burakoff R. Primary adenocarcinoma of the appendix: an unusual presentation. Am J Gastroenterol. 1995;90(4):661-2

8. Chen KT, Spaulding RW. Appendiceal carcinoma masquerading as primary bladder carcinoma. J Urol. 1991;145(4):821-2

9. Ikeda I, Miura T, Kondo I. Case of vesico-appendiceal fistula secondary to mucinous adenocarcinoma of the appendix. J Urol. 1995;153(4):1220-1.

10. Dahms SE, Hohenfellner M, Eggersmann C, Lampel A, Golz R, Thüroff JW. Appendix carcinoma invading the urinary bladder. Urol Int. 1997;58(2):124-7.

11. Arisawa C, Takeuchi SI, Wakui M. Appendiceal carcinoma invading the urinary bladder. Int J Urol. 2001;8(4):196-8.

12. Mistry R, Ananthakrishnan K, Hamid BN, Powell C, Foster GE. Appendiceal carcinoma masquerading as recurrent urinary tract infections: case report and review of literature. Urology. 2006;68(2):428-e1.

13. Vidarsdottir H, Moller PH, Benediktsdottir KR, Geirsson G. Adenocarcinoma of the appendix with a fistula to the urinary bladder. Scand J Urol Nephrol. 2010;44(5):354-6.
14. Taverna G, Corinti M, Colombo P, Grizzi F, Severo M, Piccinelli A, et al. Bladder metastases of appendiceal mucinous adenocarcinoma: a case presentation. BMC Cancer. 2010;10(1):62.

15. Wang W, Wang $L, X U$ J, Shi S, Tian $Y$, Zhang $Y$. Combination of CT imaging and endoscopy in diagnosis of appendicovesical fistula caused by appendiceal adenocarcinoma. Journal of X-ray science and technology. 2014;22(4):493-501.

16. Subramanya D, Grivas PD, Styler M. Appendiceal carcinoma: a diagnostic and therapeutic challenge. Postgrad Med. 2008;120(4):95-100.

17. Ryan, J. W., O'Riordan, I., Gorey, T., \& Geoghegan, T. (2017). de Garengeot hernia with a mucinous neoplasm of the appendix, two clinical rarities combine to yield a first for the literature. BMJ Case Rep, 2017, pii-bcr.

18. Markovich BM, Alexander AA, Gaur R, Ansari S. Recurrent peritoneal carcinomatosis in the scrotum in a patient with a history of mucocele of the appendix. J Clin Ultrasound. 2013:41:42-5.

19. Dixit A, Robertson JH, Mudan SS, Akle C. Appendiceal mucoceles and pseudomyxoma peritonei. World J Gastroenterol 2007; 13: 2381-2384. PMid: 17511043. Edge, S. B., \& Compton, C. C. (2010). The American joint committee on Cancer: the 7th edition of the AJCC cancer staging manual and the future of TNM. Ann Surg Oncol, 17(6), 1471-1474.

20. Bennett GL, Tanpitukpongse TP, Macari M, Cho KC, Babb JS. CT diagnosis of mucocele of the appendix in patients with acute appendicitis. Am J Roentgenol. 2009;192(3):W103-10.

21. Najafizadeh-sari S, Mehdizadeh H, Bagheri-baghdasht MS, Manoochehry S. Suppurative appendicitis presenting acute scrotal pain: a rare condition may confuse surgeons. Journal of surgical case reports. 2017;2017(10).

22. Shehzad KN, Riaz AA. Unusual cause of a painful right testicle in a 16-yearold man: a case report. J Med Case Rep. 2011;5(1):27.

23. Shahrudin MD. Scrotal abscess: an unusual complication of perforated appendix. Med J Malaysia. 1994;49(2):172-3.

24. Saleem MM. Scrotal abscess as a complication of perforated appendicitis: a case report and review of the literature. Cases journal. 2008;1(1):165.

25. Sagebiel TL, Mohamed A, Matamoros A, Taggart MW, Doamekpor F, Raghav $K P$, et al. Utility of Appendiceal calcifications detected on computed tomography as a predictor for an underlying Appendiceal epithelial neoplasm. Ann Surg Oncol. 2017;24(12):3667-72.

\section{Publisher's Note}

Springer Nature remains neutral with regard to jurisdictional claims in published maps and institutional affiliations.

Ready to submit your research? Choose BMC and benefit from:

- fast, convenient online submission

- thorough peer review by experienced researchers in your field

- rapid publication on acceptance

- support for research data, including large and complex data types

- gold Open Access which fosters wider collaboration and increased citations

- maximum visibility for your research: over $100 \mathrm{M}$ website views per year

At $\mathrm{BMC}$, research is always in progress.

Learn more biomedcentral.com/submissions 